\title{
Bailout screw placement in the posterior subaxial cervical spine: is a spinolaminar screw a viable option?
}

\author{
Tyler Jenkins ${ }^{1}$, Craig Kuhns ${ }^{2}$, Theodore Choma ${ }^{3}$, Michael Gallizzi ${ }^{3}$ and Ferris Pfeiffer,4* \\ ${ }^{1}$ Department of Orthopaedic Surgery, Northwestern University Feinberg School of Medicine, Chicago, IL, USA \\ ${ }^{2}$ Austin Spine Center, Austin, TX, USA \\ ${ }^{3}$ Department of Orthopaedic Surgery, University of Missouri, Columbia, MO, USA \\ ${ }^{4}$ Comparative Orthopaedic Laboratory, University of Missouri Columbia, MO, USA
}

\begin{abstract}
Study design: Cadaveric biomechanical testing.

Objective: Lateral mass screw placement is not always feasible when providing fixation to the subaxial cervical spine. When these situations arise salvage fixation techniques are required. Subaxial cervical salvage fixation techniques include the addition of fixation levels, anterior fixation, spinous process wiring, pedicle screw placement, intralaminar screw placement, and revision screw placement; each has its own drawbacks and are limited in the subaxial cervical spine. This study investigated the biomechanical stability and construct feasibility of a new salvage technique, a spinolaminar junction screw.

Methods: Seven fresh frozen cadavers were utilized to instrument fourteen subaxial cervical spinal segments. Motion segments were instrumented alternately between traditional lateral mass and experimental spinolaminar screw fixation. Five different groups were tested in a biomechanical laboratory: destablized spine, unilateral spinolaminar fixation, unilateral lateral mass fixation, bilateral fixation with spinolaminar fixation, and bilateral fixation with traditional lateral mass fixation.

Results: The destabilized group was significantly less stiff than any fixation group in all loading directions. The inclusion of instrumentation (lateral mass or spinolaminar) significantly $(\mathrm{p}<0.01)$ increased construct stiffness as compared to the destabilized group. There was a non-significant trend toward increased stiffness with bilateral fixation constructs. There was no significant difference ( $p>0.01)$ between unilateral screw groups or bilateral screw groups in any loading direction, indicating that the spinolaminar screw provides similar construct stiffness to traditional lateral mass screws.

Conclusions: A subaxial cervical spine screw oriented in the transverse plane at the spinolaminar junction may provide an alternative to lateral mass fixation and provide a salvage technique when lateral mass fixation is not available. Further studies into this screw technique should be performed prior to routine clinical placement.
\end{abstract}

\section{Introduction}

Various techniques exist for instrumenting the posterior cervical spine. Although wiring techniques have been described for more than 100 years, there are concerns that these techniques do not confer adequate torsional stability to achieve predictable fusion [1]. Certainly, the placement of cord-level sublaminar wires presents a non-trivial risk of neurological injury [2]. Posterior hook/rod constructs may be stiffer, but may require substantial space from the spinal canal. That scenario seriously threatens the spinal cord in patients with any pre-existing stenosis [3], and these can be time consuming to place properly [4]. With time, many spine surgeons have adopted lateral mass screw (LM) fixation as representing the optimal balance between rigidity and safety for fixation in the subaxial cervical spine [5].

However, there are situations when standard lateral mass screw placement is not possible. Such instances include: lateral mass screw cutout, lateral mass fractures, bony defects, and revision fixation secondary to screw loosening or malposition [6-8]. In these situations, salvage techniques are required to achieve cervical fixation. Several options exist for salvage fixation of the cervical spine such as adding extra levels of fixation, anterior fixation, spinous process wiring, cervical pedicle screw placement, interlaminar screw placement, and trans articular revision screw placement. Each of these salvage options has its own drawbacks. Adding extra levels for fixation will likely require those additional levels to be fused. Anterior plate fixation and posterior wiring constructs are not nearly as rigid in flexion or torsion as posterior screw/rod or hook/rod constructs $[1,9]$, and may require additional surgical approaches.

Cervical pedicle screw fixation is mechanically secure, but carries with it increased risk of neurovascular injury [6,10,11], without advanced navigation techniques [7,12-14]. Although certain scenarios in which the lamina are removed would allow direct visualization of the cervical pedicle, the fixation is still difficult due to pedicle anatomy in the subaxial cervical spine. However, sub-axial cervical pedicle screw fixation is a viable option when possible.

In 2004 Wright et al. described a technique for translaminar screw

Correspondence to: Ferris M Pfeiffer, Department of Orthopaedic Surgery, University of Missouri, Columbia, MO, USA, Tel: 5738840603; Fax: 5738842683; E-mail: pfeifferf@missouri.edu

Key words: spinolaminar screw, subaxial cervical, lateral mass fixation, biomechanics

Received: October 27, 2016; Accepted: November 23, 2016; Published: November 28, 2016 
fixation of C2 [15]. The translaminar technique has been proven by numerous studies to be a viable option for posterior stabilization of C2 [16-20]. Subaxial translaminar screw fixation was first introduced by Hong et al. in 2008 [21]. Numerous studies have examined the biomechanics and anatomic feasibility of subaxial translaminar screw fixation [21-25]. As of this time, C7 is the only subaxial cervical level thought to be anatomically safe enough for routine translaminar fixation [8,21-24]. This is due to the thin lamina and anatomic variability associated with the C3-C6 levels. As such, the placement of subaxial translaminar screws can prove challenging [9].

With this background, we set out to investigate the biomechanical stability and construct feasibility of another salvage technique for posterior subaxial cervical spine fixation - the use of a spinolaminar junction screw (SL) (Figures 1-3) - that is oriented in a near transverse plane at the spinolaminar junction in the subaxial cervical spine (C3C6).

This screw provides the benefits of direct visualization of screw placement, minimal neurovascular risk, bicortical fixation, and the screw is amenable to the anatomic restraints of the C3-C6 cervical levels provided that the posterior elements are present.

\section{Materials and methods}

Seven fresh frozen human cadaveric cervical spines were used in this study with mean DXA T-score -0.6 and with a STD of 2.8. Five additional specimens were excluded from the study due to DXA

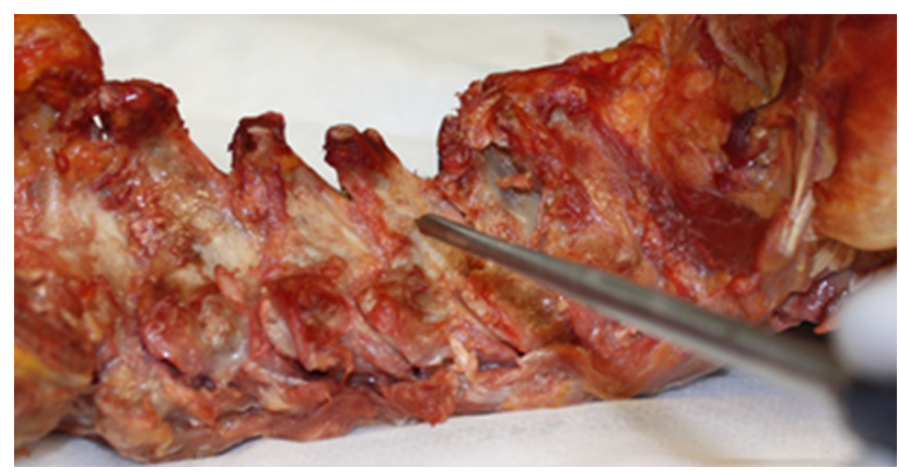

Figure 1. Starting point and trajectory for placement of spinolaminar (SL) screw at C4.

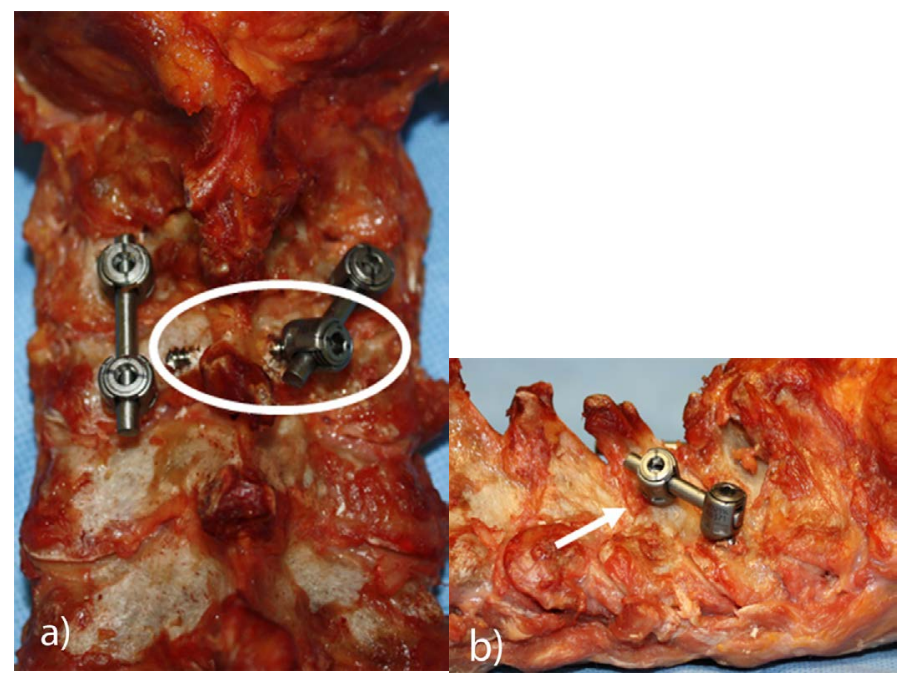

Figure 2. C3-C4 hybrid construct with spinolaminar screw (circled in 2a, arrow in 2b) and lateral mass screw fixation.
T-scores $<-2.5$; set in attempt to exclude specimens with poor bone quality. Fourteen subaxial cervical spinal motion segments were instrumented. 2 Motion segments were instrumented, at C3-4 and C5-6 were instrumented alternately between lateral (LM) and spinolaminar (SL) screw fixation which allowed us to control for specimen-tospecimen variation in BMD.

Lateral mass screws were placed with a standard technique starting just inferior and medial to the center of the lateral mass and drilling in a cephalad and lateral trajectory using a $2.5 \mathrm{~mm}$ drill. The screw path was not tapped prior to placement of $3.5 \times 14 \mathrm{~mm}$ screws in the lateral masses. Spinolaminar screws were placed with the starting point at the junction between the spinous process and lamina. A $2.5 \mathrm{~mm}$ drill was used with a near horizontal trajectory achieving a bicortical channel at the base of the spinous process/laminar junction. The path was then tapped with a $3.0 \mathrm{~mm}$ tap through both cortices and then a $3.5 \mathrm{~mm}$ screw was placed. The screw lengths varied between $14-16 \mathrm{~mm}$ in order to make sure at least two screw threads were beyond the contralateral cortex. Computed tomography (CT) scans were taken to evaluate screw placement (Figure 4).

Prior to testing the C3-4 and C5-6 motion segments, a scalpel was used to circumferentially transect the facet capsules at those levels in order to partially destabilize the segments. For all samples, C7 was left uninstrumented and was fixed rigidly to the table of a servo-hydraulic (Instron 8821s) load frame. C2 (without instrumentation) was attached

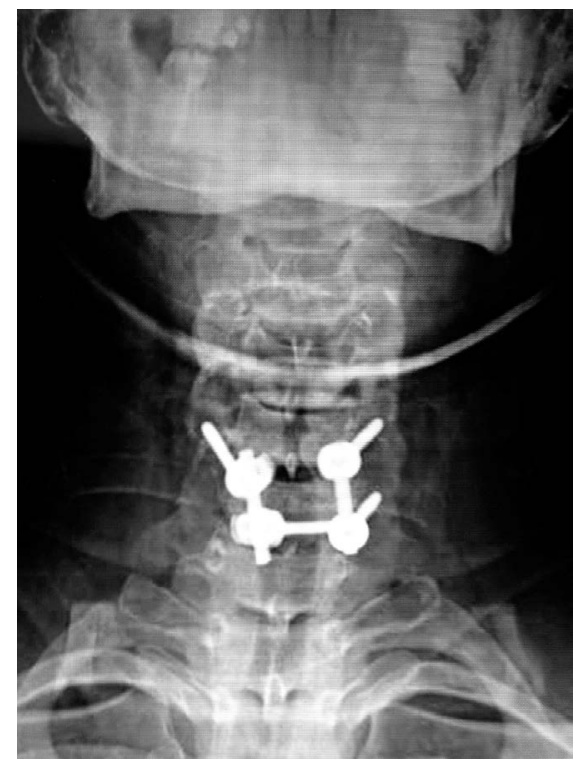

Figure 3. AP cervical spine XR showing the use of a spinolaminar junction screw as bailout technique in clinical practice.

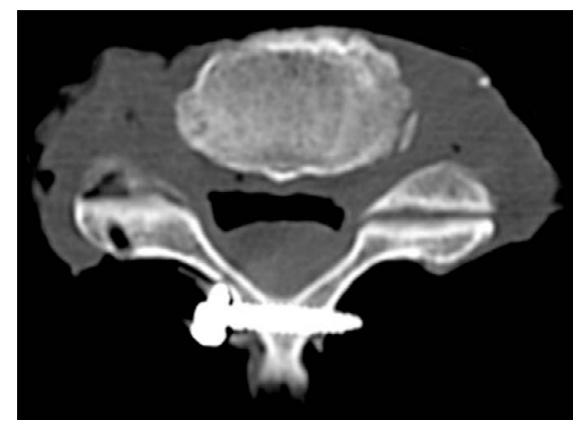

Figure 4. Axial cut CT scan of $\mathrm{C} 4$ spinolaminar screw in a cadaver specimen. 
to the Instron ram using a custom gripping fixture (Figure 5). Center of rotation was found in accordance with our previously published methods [26], afterwhich the offset loading arm was translated $5 \mathrm{~mm}$ (relative to the center of rotation), anteriorly, posteriorly, or laterally in order to apply sub-failure flexion, extension, and lateral bend loading respectively. Groups tested included:

- Destabilized Spine

- Unilateral Spinolaminar (SL-LM): spinolaminar screw connected to a lateral mass screw

- Unilateral Lateral Mass (LM-LM): 2 lateral mass screws connected through a bar

- Bilateral Fixation with a spinolaminar screw (SL_LM on one side and LM-LM on contralateral side)

- Bilateral Fixation with LM (LM-LM on one side and LMLM on contralateral side)

This configuration allowed us to test the construct that would most likely be encountered clinically where a unilateral LM screw was salvaged with a SL screw; this was connected to a normal construct of LM screws (Figure 3 shows a clinical example of the construct). Prior to biomechanical testing, all specimens underwent CT specifically looking for any violation of the ventral lamina or central canal by the SL screws.

Bending moments (up to $3 \mathrm{~N}-\mathrm{m}$ under displacement control at $1 \mathrm{~mm} / \mathrm{s}$ ) were applied using an offset loading arm for successive testing of destabilized, unilaterally, and bilaterally instrumented segments (Figure 5). Each specimen was first tested in the destabilized configuration. The testing order of subsequent fixation configurations (i.e. unilateral spinolaminar screw (SL-LM), unilateral lateral mass screws(LM-LM), bilateral fixation with a spinolaminar screw (SLLM on one side and LM-LM on contralateral side), and bilateral fixation with LM (LM-LM on one side and LM-LM on contralateral side) was randomized in order to minimize artifects due to testing order. Relative motion at each segment was continuously monitored using a NDI Certus 3D optical tracking system with one target placed on the inferior vertebra and a second on the superior vertebra of the segment in question (Figure 5). Relative displacement and construct

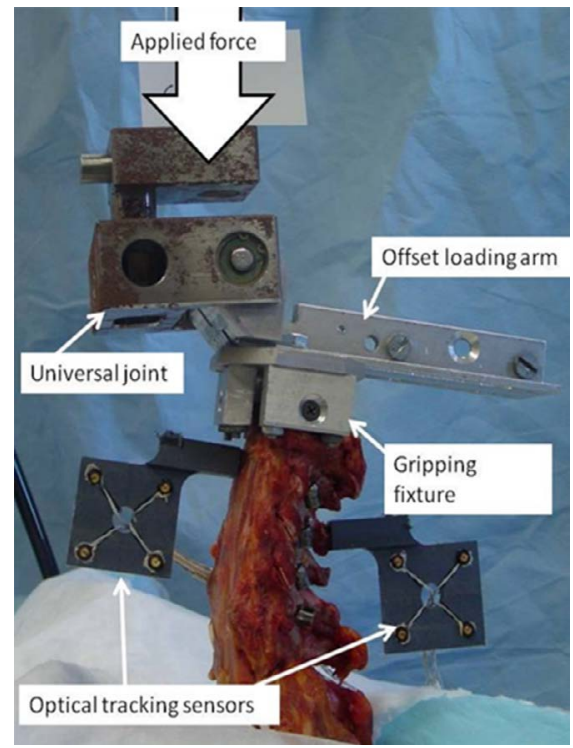

Figure 5. Test setup with gripping fixture, loading arm (setup for flexion), and optical tracking sensors attached. stiffness were compared for each group. In order to reduce interspecimen variability, values were normalized with respect to the destabilized control. Analysis of variance (ANOVA) was performed for statistical analysis.

\section{Results}

The destabilized group demonstrated considerably less stiffness than any fixation group in all loading directions and was consistent with what is observed physioloigically and has been reported previously [27]. Figure 6 demonstrates our results in chart format. The inclusion of instrumentation (either lateral mass or spinolaminar) significantly $(\mathrm{p}<0.01)$ increased construct stiffness as compared to the destabilized group. There was a non-significant trend toward increased stiffness with bilateral fixation constructs. There was no significant difference ( $p>0.01$ ) between unilateral screw groups or bilateral screw groups in any loading direction, indicating that the spinolaminar screw placement provides similar construct stiffness to traditional lateral mass screws (Figure 6). CT scans of each cadaveric specimen confirmed bicortical placement of the SL screws at the spinolaminar junction with no breaches of the ventral lamina.

\section{Discussion}

The placement of a transverse oriented spinolaminar screw is a potential C3-C6 salvage fixation option with some obvious benefits. The landmarks for the spinolaminar junction screw are directly visible to the surgeon. Screw placement in this orientation does not breech cortices adjacent to the spinal canal or the transverse foramen and should present minimal risk for neurovascular damage, although this has not been assessed in any clinical series to the authors' knowledge.

Our study showed that the stiffness in flexion, extension, and lateral bending of an SL screw construct had no statistical $(p>0.01)$ difference when compared to the traditional lateral mass screw fixation in the subaxial cervical spine. This may support the use of an SL screw construct as a possible bailout procedure for posterior fixation when lateral mass screw placement is not possible.

There are several limitations to this initial study. Since this is a cadaveric study, we had no way to model active muscle forces nor the remodeling response of bone adjacent to any of the screws placed. One might imagine a live animal model employed to study some aspects of these phenomena. This study only analyzed 1-level constructs and

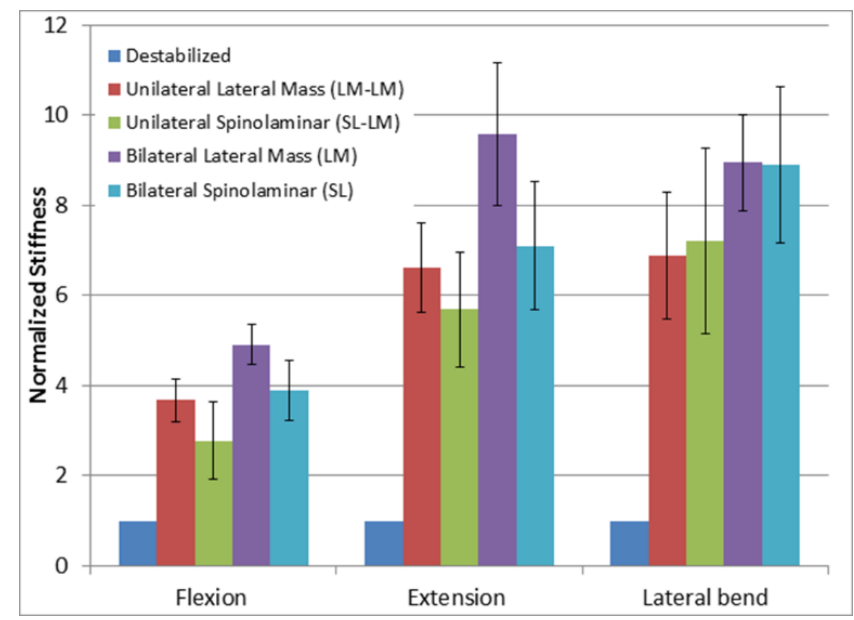

Figure 6. Measured construct stiffness in flexion, extension, and lateral bending with values normalized to the unstable control. 
with the addition of more levels mechanical differences may present between SL fixation and LM constructs. We have not assessed the effect of SL fixation in osteopenia / osteoporosis. It may be that there is a significant difference between SL and LM fixation in those instances. We have also not investigated the effects of varying screw diameter in SL fixation. We chose $3.5 \mathrm{~mm}$ screws as they are commonly available in most posterior cervical fixation instrumentation systems.

The spinolaminar junction screw does have certain clinical limitations that could hinder its use during certain scenarios. First, the spinolaminar junction construct is predicated on stable and intact bony anatomy of the posterior cervical elements; specifically, the lamina and a majority of the spinous process must be intact for fixation. Patients that have had prior laminectomies, spinous process removal, or bony defects involving the spinous process or lamina would not be candidates for this construct. Second, the transverse or near-transverse orientation of the screw may prove challenging in patients with significant amounts of posterior neck soft tissue and may prevent its use in such patients. Third, we have not addressed the logistics of including SL fixation in the midst of a long-segment construct. One could imagine some difficulty in this circumstance. However, SL fixation could prove especially useful for the subaxial cervical levels of C3-C6 since interlaminar and pedicle screws can prove quite challenging.

In conclusion, spinolaminar junction screw placement in the subaxial cervical spine provides similar construct stiffness to traditional lateral mass screw fixation ( $\mathrm{p}>0.01$ ). Our findings suggest that a screw - oriented in the near transverse plane at the spinolaminar junction in the C3-C6 segments - may provide a relatively safe alternative to lateral mass fixation and provide surgeons with a legitimate salvage option if a lateral mass screw is not able to be placed.

\section{Acknowledgment}

Stryker Spine provided in- kind support (posterior cervical implants and instrumentation) for this study. Two authors have consulting relationships with Stryker Spine, but received no payments related to this study.

\section{References}

1. Coe JD, Warden KE, Sutterlin CE 3rd, McAfee PC (1989) Biomechanical evaluation of cervical spinal stabilization methods in a human cadaveric model. Spine (Phila, PA 1976) 14: 1122-1131. [Crossref]

2. Wilber RG, Thompson GH, Shaffer JW, Brown RH, Nash CL Jr (1984) Postoperative neurological deficits in segmental spinal instrumentation. A study using spinal cord monitoring. J Bone Joint Surg Am 66: 1178-1187. [Crossref]

3. Fagerström T, Hedlund R, Bancel P, Robert R, Dupas B (2001) Laminar hook instrumentation in the cervical spine. An eperimental study on the relation of hooks to the spinal cord. Eur Spine J 10: 340-344. [Crossref]

4. Hildinqsson C, Jonsson H (2001) Posterior stabilization of the cervical spine with hooks and screws. A clinical evaluation of 26 patients with traumatic, degenerative or metastatic lesions, using a new implant system. Eur Spine J 10: 50-54.

5. Coe JD, Vaccaro AR, Dailey AT, Skolasky RL Jr, Sasso RC, et al. (2013) Lateral mass screw fixation in the cervical spine: a systematic literature review. J Bone Joint Surg Am 95: 2136-2143. [Crossref]

6. Fehlings MG, Cooper PR, Errico TJ (1994) Posterior plates in the management of cervical instability: long-term results in 44 patients. J Neurosurg 81: 341-349. [Crossref]

7. Shin EK, Panjabi MM, Chen NC, Wang JL (2000) The anatomic variability of human cervical pedicles: considerations for transpedicular screw fixation in the middle and lower cervical spine. Eur Spine J 9: 61-66. [Crossref]

8. Shin SI, Yeom JS, Kim HJ, Chang BS, Lee CK (2012) The feasibility of laminar screw placement in the subaxial spine: analysis using 215 three-dimensional computed tomography scans and simulation software. Spine J 12: 577-584. [Crossref]
9. Molina C, Kretzer RM, Hu N, Umekoji H, Cunningham B, et al. (2014) Comparative in vitro biomechanical analysis of a novel posterior cervical fixation technique versus conventional posterior-based constructs. J Spinal Disord Tech 27: 40-47.

10. Abumi K, Shono Y, Ito M, Taneichi H, Kotani Y, et al. (2000) Complications of pedicle screw fixation in reconstructive surgery of the cervical spine. Spine (Phila Pa 1976) 25: 962-969. [Crossref]

11. Choueka J, Spivak JM, Kummer FJ, Steger T (1996) Flexion failure of posterior cervical lateral mass screws. Influence of insertion technique and position. Spine (Phila $\mathrm{Pa}$ 1976) 21: 462-468. [Crossref]

12. Kothe R, Rüther W, Schneider E, Linke B (2004) Biomechanical analysis of transpedicular screw fixation in the subaxial cervical spine. Spine (Phila Pa 1976) 29: 1869-1875. [Crossref]

13. Kwon BK, Vaccaro AR, Grauer JN, Beiner JM (2007) The use of rigid internal fixation in the surgical management of cervical spondylosis. Neurosurgery 60: S118-S129.

14. Nakashima H, Yukawa Y, Imagama S, Kanemura T, Kamiya M, et al. (2012) Complications of cervical pedicle screw fixation for nontraumatic lesions: a multicenter study of 84 patients. J Neurosurg Spine 16: 238-247. [Crossref]

15. Wright NM (2004) Posterior C2 fixation using bilateral, crossing C2 laminar screws: case series and technical note. J Spinal Disord Tech 17: 158-162. [Crossref]

16. Bhatnagar R, Yu WD, Bergin PF, et al. (2010) The anatomic suitability of the C2 vertebra for intralaminar and pedicular fixation: a computed tomography study. Spine $J$ 10: 896-899. [Crossref]

17. Dorward IG, Wright NM, Matteini LE, O'Brien JR (2011) Seven years of experience with $\mathrm{C} 2$ translaminar screw fixation: clinical series and review of the literature. Neurosurgery 68: 1491-1499. [Crossref]

18. Jea A, Sheth RN, Vanni S, Green BA, Levi AD (2008) Modification of Wright's technique for placement of bilateral crossing $\mathrm{C} 2$ translaminar screws: technical note. Spine J 8: 656-660. [Crossref]

19. Ma XY, Yin QS, Wu ZH, Xia H, Riew KD, et al. (2010) C2 anatomy and dimensions relative to translaminar screw placement in an Asian population. Spine (Phila Pa 1976) 35: 704-708. [Crossref]

20. Sciubba DM, Noggle JC, Vellimana AK, Conway JE, Kretzer RM, et al. (2008) Laminar screw fixation of the axis. J Neurosurg Spine 8: 327-334. [Crossref]

21. Hong JT, Sung JH, Son BC, Lee SW, Park CK (2008) Significance of laminar screw fixation in the subaxial cervical spine. Spine (Phila Pa 1976) 33: 1739-1743. [Crossref]

22. Cardoso MJ, Dmitriev AE, Helgeson MD, Stephens F, Campbell V, et al. (2009) Using lamina screws as a salvage technique at C-7: computed tomography and biomechanical analysis using cadaveric vertebrae. Laboratory investigation. $J$ Neurosurg Spine 11: 28-33.

23. Hong JT, Tomoyuki T, Udayakumar R, Espinoza Orías AA, Inoue N, et al. (2011) Biomechanical comparison of three different types of $\mathrm{C} 7$ fixation techniques. Spine (Phila Pa 1976) 36: 393-398. [Crossref]

24. Hong JT, Yi JS, Kim JT, Ji C, Ryu KS, et al. Clinical and radiologic outcome of laminar screw at $\mathrm{C} 2$ and $\mathrm{C} 7$ for posterior instrumentation - review of 25 cases and comparison of C2 and C7 intralaminar screw fixation. World Neurosurg 73: 112-1128. [Crossref]

25. Nakanishi K, Tanaka M, Sugimoto Y, Misawa H, Takigawa T, et al. (2008) Application of laminar screws to posterior fusion of cervical spine: measurement of the cervical vertebral arch diameter with a navigation system. Spine (Phila, PA 1976) 33: 620-633.

26. Choma T, Pfeiffer F, Vallurupalli S, Mannering I, Pak Y (2012) Segmental stiffness achieved by three types of fixation for unstable lumbar spondylolytic motion segments. Global Spine J 2: 79-86. [Crossref]

27. Panjabi MM, Crisco JJ, Vasavada A, Oda T, Cholewicki J et al. (2001) Mechanical properties of the human cervical spine as shown by three-dimensional loaddisplacement curves. Spine (Phila, Pa 1976) 26: 2692-2700. [Crossref]

Copyright: (C2016 Jenkins T. This is an open-access article distributed under the terms of the Creative Commons Attribution License, which permits unrestricted use, distribution, and reproduction in any medium, provided the original author and source are credited. 